\title{
Identification of Metal-Associated Proteins in Cells by Using Continuous-Flow Gel Electrophoresis and Inductively Coupled Plasma Mass Spectrometry**
}

\author{
Ligang Hu, Tianfan Cheng, Bin He, Lu Li, Yuchuan Wang, Yau-Tsz Lai, Guibin Jiang, and \\ Hongzhe Sun*
}

Metals and metalloids are crucial for life and indispensable for a series of biological processes. ${ }^{[1]}$ It is estimated that a quarter to one third of all proteins require metals to carry out their functions, and roughly half of the known enzymes uses a particular metal as a cofactor. ${ }^{[2]}$ In spite of the prevalence and importance of metalloproteins, they are generally poorly characterized in many organisms. A recent study demonstrated that the microbial metalloproteome is much more extensive and diverse than we presently know. ${ }^{[3]}$ Currently, it is impossible to predict, genome-wide, the numbers and types of metals used by organisms and to define any metalloproteome until the proteins are fully characterized owing to diverse and poorly recognized metal coordination sites. Moreover, metals/metalloids have long been used for therapeutic purposes, for example, arsenic trioxide for the treatment of acute promyelocytic leukemia. ${ }^{[4]}$ The detailed molecular mechanisms, however, are still not fully understood owing to the complex functions of metals in biological systems. ${ }^{[5]}$ A robust and convenient approach, by which metals/metalloids can be mapped to their associated proteins proteome-wide is urgently needed. ${ }^{[6]}$ Such a methodology will improve our understanding of the molecular mechanisms of metal-dependent biological processes and profoundly promote metallomics research, ${ }^{[7]}$ an integrated biometal science complementary to genomics and proteomics. ${ }^{[8]}$ Gel electrophoresis has been one of the commonly used methods for separation and analysis of proteins based on their molecular mass and charge; however, it fails to provide information on metal identity and content for metalloproteins. The lack of convenient subsequent methods for specific metal detection confines its application on providing metalrelated information of corresponding proteins. Although laser

[*] Dr. L. Hu, Dr. T. Cheng, Dr. B. He, Y. Wang, Y.-T. Lai, Prof. H. Sun Department of Chemistry, The University of Hong Kong

Pokfulam, Hong Kong (P. R. China)

E-mail: hsun@hku.hk

Dr. B. He, Dr. L. Li, Prof. G. Jiang

Research Center for Eco-Environmental Sciences

Chinese Academy of Sciences

No. 8 Shuangqing Road, Haidian District, Beijing, 100085 (China)

[**] This work was supported by NSFC/RGC joint research Scheme of RGC (N_HKU75209), the Special Equipment Grant of the UGC of the Hong Kong SAR (SEG_HKU02) and the NSFC (21277151). The University of Hong Kong and Croucher Foundation are also acknowledged for financial support.

Dupporting information for this article is available on the WWW under http://dx.doi.org/10.1002/anie.201300794. ablation inductively coupled plasma mass spectrometry (LAICP-MS) ${ }^{[9]}$ and synchrotron X-ray fluorescence spectrometry $(\mathrm{SXFS})^{[10]}$ have been used for the identification of metalbinding proteins on gels and in tissues/organs, either compromised sensitivity originating from the sample introduction system or limited accessibility to the synchrotron facility prevents their routine applications. Other strategies such as metal isotope radioautography, which employs unique metal isotopes to label metalloproteins, are also very inconvenient for daily usage. ${ }^{[11]}$

Herein, a new strategy based on column-type gel electrophoresis coupled with a metal-specific detection system, that is ICP-MS, was developed (Figure 1a), allowing both metals and their associated proteins to be examined comprehensively. Since the strategy can be used to analyze and at the same time to separate and isolate proteins, it can readily be applied to not only detect metalloproteins and/or metalbound proteins with a sensitivity at the femtomole level, but also conveniently integrate current proteomics with metallomics. We further showed the bismuth profile in cell lysates of Helicobacter pylori upon treatment with colloidal bismuth subcitrate (CBS) and further characterized metal-binding features of H. pylori SlyD (HpSlyD) inside cells.

The column-type gel adopted the traditional slab gel preparation. Both native and denaturing conditions could be applied, and the gel compositions varied with the protein targets of interest. To validate the feasibility of the column gel system, three metal-binding proteins, $\mathrm{Cu}$-bound bovine serum albumin (Cu-BSA), $\mathrm{Cu}, \mathrm{Zn}$ superoxide dismutase $(\mathrm{Cu}, \mathrm{Zn}$ $\mathrm{SOD})$, and diferric transferrin $\left(\mathrm{Fe}_{2}-\mathrm{Tf}\right)$, were mixed and subjected to separation. Three bands, corresponding to $\mathrm{Fe}_{2}-$ Tf, $\mathrm{Cu}, \mathrm{Zn}-\mathrm{SOD}$, and BSA, were visualized on a CoomassieBlue-stained slab gel (Figure $1 \mathrm{~b}$ ). The proteins separated by column-type gel electrophoresis gave rise to migration profiles similar to those observed in classical slab gel under comparable conditions. The elutes from the column gel system were split into two parts by using a $\mathrm{T}$ connection, with one for online metal measurement by ICP-MS and the other for protein identification through biological mass spectrometry analysis of the collected fractions (Figure $1 \mathrm{a}$ ). It is noted that one peak was observed in either the ${ }^{66} \mathrm{Zn}$ or ${ }^{57} \mathrm{Fe}$ profile corresponding to SOD and transferrin, respectively, indicative of association of $\mathrm{Zn}^{\mathrm{II}}$ ions with SOD and binding of $\mathrm{Fe}^{\mathrm{III}}$ ions to Tf; whereas there are two peaks in the ${ }^{63} \mathrm{Cu}$ profile, with each corresponding to a distinct molecular mass, thus suggesting that copper binds to both SOD and BSA. The amounts of metals were quantifiable (Figure S2 in 
a Gel electrophoresis system

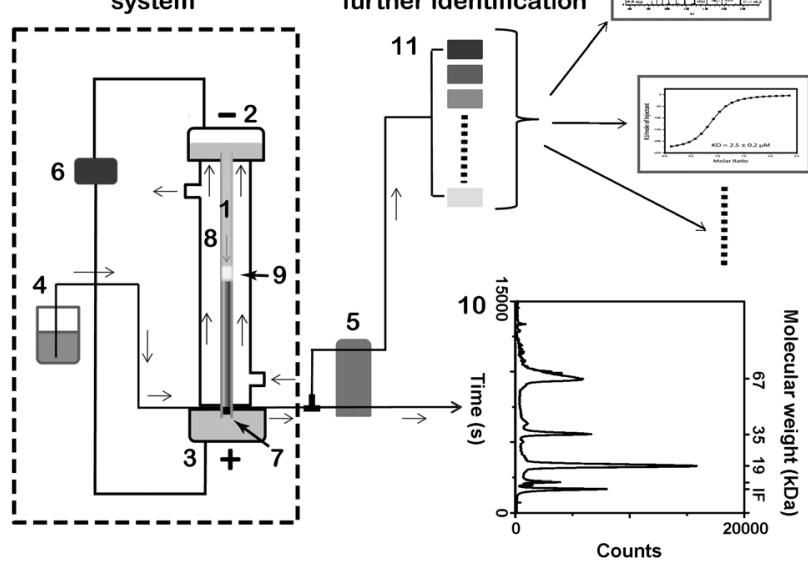

ICP-MS for metal identification

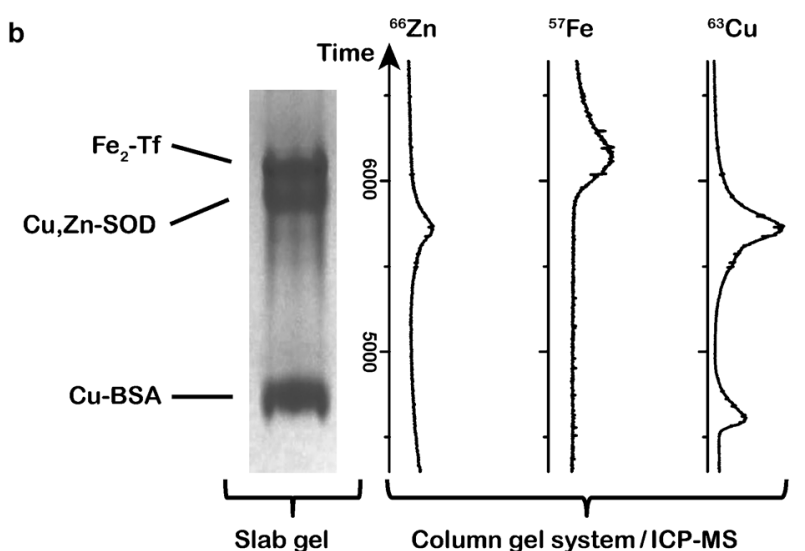

Figure 1. a) Illustration of the column gel system, which consists of a gel electrophoresis system, a metal-specific detection system (ICPMS), and a fraction collector. 1. Gel column; 2. upper running buffer; 3. lower running buffer; 4. elution buffer; 5 . peristaltic pump; 6. power supply; 7. dialysis membrane; 8 . cooling system; 9 . loaded sample; 10. proteins are separated according to molecular weight and analyzed by ICP-MS; 11. fractions can be further analyzed by, for example, MS (upper arrow) or ITC (arrow below). b) Profiles of metals $\left({ }^{66} \mathrm{Zn},{ }^{57} \mathrm{Fe}\right.$, and ${ }^{63} \mathrm{Cu}$ ) measured by ICP-MS after separation by the column-type gel electrophoresis. On the $y$-axis, the time of elution (seconds) is plotted, which corresponds to a certain molecular weight. The corresponding proteins (Cu-BSA, $\mathrm{Cu}, \mathrm{Zn}-\mathrm{SOD}$, and $\mathrm{Fe}_{2}-\mathrm{Tf}$ ) separated by using a slab gel (stained with Coomassie Blue) are shown for comparison.

the Supporting Information) with a sensitivity at a level of tens of femtomoles ( $26 \mathrm{fmol}$, the Supporting Information). The achieved sensitivity was significantly better than that of other strategies in monitoring metal/protein complexes after separation by gel electrophoresis, for example, typical detection limits for the LA-ICP-MS system even with a powerful femtosecond laser source are at the sub-parts-per-million level. ${ }^{[12]}$

We then use colloidal bismuth subcitrate (CBS, De-Nol) as an example to track the metallodrug-binding proteins in $H$. pylori, a pathogen leading to gastrointestinal diseases and even stomach cancer. ${ }^{[13]}$ Bismuth-based drugs have long been used for the treatment of the bacterial infection and peptic ulcer together with antibiotics. ${ }^{[14]}$ Selected proteins have been reported to be up- or down-regulated upon the treatment of H. pylori with CBS and further validated ${ }^{[15]}$ Nevertheless the underlined molecular mechanism of action of bismuth drugs is still not fully understood.

H. pylori 26695 was cultured in the presence of CBS $\left(20 \mu \mathrm{g} \mathrm{mL}^{-1}\right)$, and the cell lysates were analyzed by using our current system. As shown in Figure 2, Bi-associated peaks

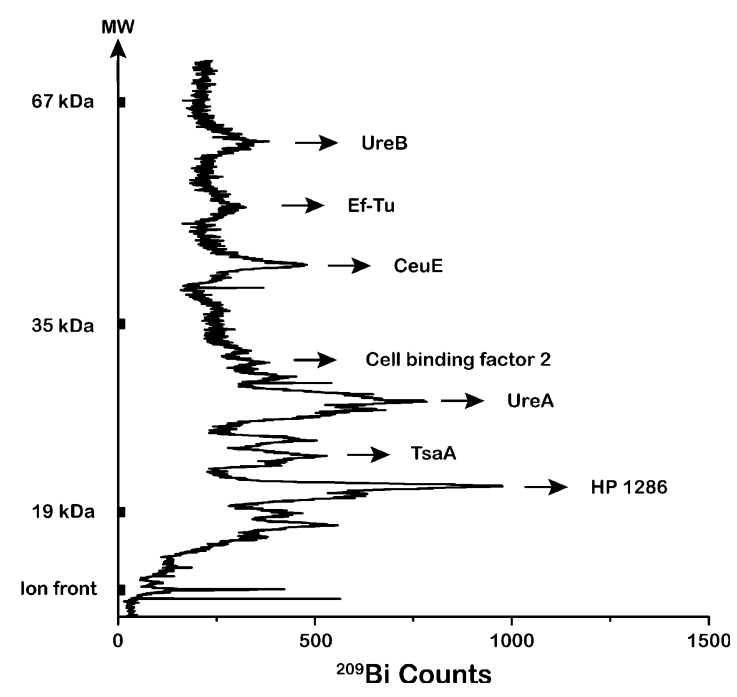

Figure 2. Profile of Bi-binding proteins in H. pylori (strain 26695) measured with the gel electrophoresis system after treatment of the pathogens with CBS $\left(20 \mu \mathrm{g} \mathrm{mL}^{-1}\right)$. A reverse multi-layered gradient gel was optimized and used for the separation. The molecular weights were evaluated by using standard protein markers consisting of a series of metal-labeled proteins and the $y$-axis was plotted accordingly (see the Supporting Information).

with an apparent molecular weight less than $67 \mathrm{kDa}$ were observed for the cell lysate, thereby demonstrating that the system is able to separate proteins with high resolution. The $x$ axis shows the counts (concentration) of ${ }^{209} \mathrm{Bi}$, and the $y$-axis the molecular weights, which were referenced to the $\mathrm{Hg}$ labeled protein markers (see the Supporting Information). According to the apparent molecular weights calculated from the makers and a previous report, ${ }^{[15 b]}$ seven proteins were tentatively assigned (Figure 2). The corresponding peaks were fractionized, collected, and subjected to MALDITOF-MS analysis after a purification step. Proteins corresponding to each peak in Figure 2 were identified through peptide mass fingerprinting, which confirmed our tentative assignments; the results are summarized in Table S1-7 in the Supporting Information.

Till now, none of the protein targets of a Bi-based drug in H. pylori has ever been unequivocally identified. UreA and UreB are the subunits of urease, an enzyme catalyzing hydrolysis of urea to ammonia and carbon dioxide, and thereby neutralizing the acidic environment around the bacteria. ${ }^{[16]}$ The enzyme is critical for H. pylori colonization in the human stomach, and has been regarded as a valid target for the treatment of $H$. pylori infection. Other identified 
proteins are also important for various functions of bacteria. Ef-Tu, belonging to the GTP-binding elongation factor family, promotes the binding of tRNA to ribosomes during protein biosynthesis. ${ }^{[17]}$ TsaA, a thiol-specific antioxidant, acts against intracellular oxidative stress. ${ }^{[18]}$ HP1286, a hypothetical protein, contains a conserved YceI-like domain, and its homologue in Thermus thermophilus plays an important role in isoprenoid quinone metabolism and/or transport and/or storage ${ }^{[19]} \mathrm{CeuE}$ is the iron(III) ABC transporter periplasmic iron-binding protein $;^{[20]}$ whereas cell binding factor 2 is a secreted peptidyl-prolyl cis/trans-isomerase, which may bind to toll-like receptor 4 and trigger the signaling pathway. ${ }^{[21]}$ The observation of such a Bi profile implied that the Bi-based drug inhibits the pathogen in a unique manner through acting on multiple protein targets. It will be of interest to further examine the potential functional changes of these proteins induced by the metal drug.

We subsequently used the method to investigate proteinassociated metals on a metallome-wide scale using HpSlyD expressed in Escherichia coli as a model. SlyD is a member of the FK506-binding protein (FKBP) family, which possesses peptidyl-prolyl cis/trans-isomerase (PPIase) and chaperone activities. ${ }^{[22]}$ A recent study demonstrated that HpSlyD was positively related to the $H$. pylori associated gastric cancer, and may be used as a biomarker and potential drug target. ${ }^{[23]}$ Interestingly, it possesses a histidine- and cysteine-rich domain at the Cterminus $\left({ }^{152}\right.$ ILASHHGGGTGCCGGHGGHGGKKGGGCGCSCS $H^{185}$ ). Various transition metals $(\mathrm{Zn}, \mathrm{Ni}, \mathrm{Cu}$, and $\mathrm{Co}$ ) have been proposed to bind SlyD in vitro, and metals may also play a role in the function of the protein. ${ }^{[22 b, 24]}$ The role of metals associated with SlyD in vivo remains unclear.

Upon loading the crude cell lysate of E. coli overexpressing HpSlyD to the gel electrophoresis system, several metalassociated peaks were clearly observed. Mass-spectrometry-

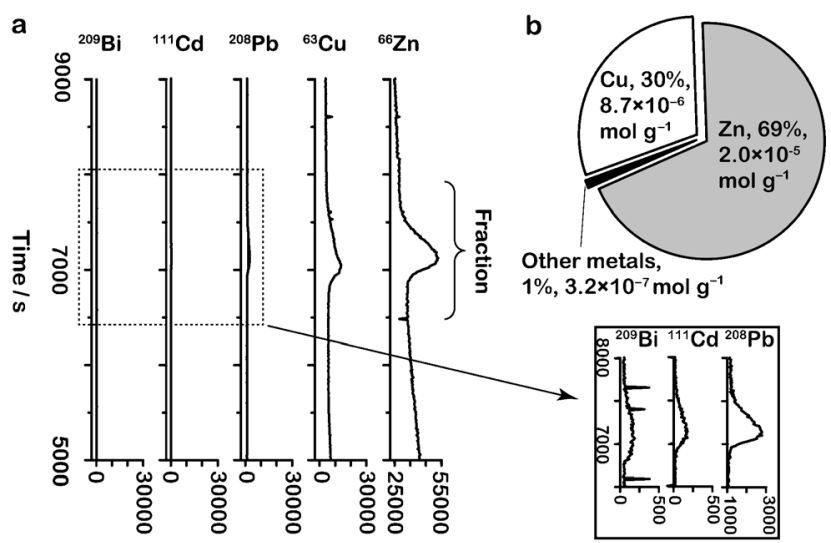

Figure 3. Crude lysate of E. coli expressing HpSlyD analyzed with the gel electrophoresis system. a) Metal profiles with one peak in each profile further identified as HpSlyD. The $x$-axis shows the counts of the respective metal. b) Distribution of metals associated with HpSlyD. Inset: Zoom in of the ICP-MS spectra of $\mathrm{Bi}, \mathrm{Cd}$, and $\mathrm{Pb}$ of the collected fraction showing that trace amounts of metal-binding proteins could be monitored, for example the peak intensities of $\mathrm{Bi}$ - and $\mathrm{Cd}$-bound forms of HpSlyD were as low as hundreds of counts, corresponding to only hundreds of femtomole of metal/HpSlyD complex. based peptide mass fingerprinting on the collected fractions confirmed that one major peak corresponds to $H p S l y D$ (Table S8 in the Supporting Information), and the metal profiles are shown in Figure 3. Further mass spectrometry and isothermal titration calorimetry (ITC) data confirmed that $H p$ SlyD binds these metals with binding constants $\left(K_{\mathrm{d}}\right)$ of 1.4 and $2.6 \mu \mathrm{M}$ for $\mathrm{Pb}^{\mathrm{II}}$ and $\mathrm{Cd}^{\mathrm{II}}$, respectively, (Figure $\mathrm{S} 3$ in the Supporting Information). ESI-MS data obtained under the native condition also demonstrated the association of $H p S l y D$ with $\mathrm{Pb}^{\mathrm{II}}$ and $\mathrm{Cd}^{\mathrm{II}}$ (Figure S4 in the Supporting Information).

To further examine whether metals bind specifically at the C-terminal histidine- and cysteine-rich domain, an HpSlyD variant lacking the $\mathrm{C}$ terminus $(H p S l y D \Delta C)$ was constructed and expressed in E. coli under identical conditions. Little metal corresponding to the $H p S l y D \Delta C$ fraction was detected by using the gel electrophoresis system (Figure S5 in the Supporting Information), thus confirming that these metals bind the protein at the $\mathrm{C}$ terminus. It is commonly believed that both cysteine and histidine serve as metal-binding residues. To identify whether these residues in the $\mathrm{C}$ terminus of $H p$ SlyD are critical for such binding, two $H p S l y D$ variants, that is, HpSlyD-CmutA and HpSlyD-HmutA with all cysteines and histidines mutated to alanines, respectively, were constructed and used to carry out similar experiments. For the cells expressing HpSlyD-CmutA no metal peaks were observed (Figure S6 in the Supporting Information), thereby indicating that the protein did not bind to any metal ions; whereas the cell expressing HpSlyD-HmutA gave rise to extremely weak peaks of $\mathrm{Zn}, \mathrm{Cu}, \mathrm{Pb}$, and $\mathrm{Bi}$ compared with those for the wild-type protein. Taken together, cysteine and histidine residues in the $\mathrm{C}$ terminus of $\mathrm{HpSlyD}$ are identified to be the key residues coordinated to metal ions.

Unexpectedly, when E. coli cells were aerobically cultured in LB medium, HpSlyD exhibits binding towards $\mathrm{Cu}$, $\mathrm{Zn}, \mathrm{Cd}, \mathrm{Pb}, \mathrm{Bi}$ (Figure 3) amongst 26 metals of interest i.e., $\mathrm{Mg}, \mathrm{Al}, \mathrm{Ca}, \mathrm{Sc}, \mathrm{Ti}, \mathrm{V}, \mathrm{Cr}, \mathrm{Mn}, \mathrm{Fe}, \mathrm{Co}, \mathrm{Ni}, \mathrm{Cu}, \mathrm{Zn}, \mathrm{Ga}, \mathrm{Ge}, \mathrm{Se}$, $\mathrm{Mo}, \mathrm{Ag}, \mathrm{Cd}, \mathrm{In}, \mathrm{Sn}, \mathrm{W}$, and $\mathrm{Bi}$, which include all essential metals/metalloids measured except for $\mathrm{Na}$ and $\mathrm{K}^{[25]}$ In particular, $H p$ SlyD preferentially binds $\mathrm{Zn}$ followed by $\mathrm{Cu}$, with the percentages of bound metals being $69 \%$ and $30 \%$, respectively, while other metal ions account for less than $1 \%$ (Figure $3 \mathrm{~b}$ ). Surprisingly, Ni does not bind to HpSlyD in vivo, in contrast to a previous in vitro study. ${ }^{[26]}$ It is intriguing that $H p S l y D$ showed a high selectivity towards $\mathrm{Zn}$ and $\mathrm{Cu}$ given the moderate amounts of $\mathrm{Zn}(13.4 \mu \mathrm{M})$ and $\mathrm{Cu}(3.3 \mu \mathrm{M})$ found in the culture medium compared with other metals with relatively high contents (e.g. $\mathrm{Mg}(>41.2 \mu \mathrm{M}) ; \mathrm{Ca}(26.8 \mu \mathrm{M}) ; \mathrm{Fe}$ $(9.4 \mu \mathrm{M})$; Table $\mathrm{S} 4$ in the Supporting Information). Importantly, the relative ratios of bound $\mathrm{Zn}$ and $\mathrm{Cu}$ to the protein kept nearly unchanged (Figure S6), even when the amounts of metals in the culture medium were elevated $(\mathrm{Ni}, \mathrm{Cu}, \mathrm{Fe}, \mathrm{Co}$ to ca. $10 \mu \mathrm{M}$ ). It will be of interest to further investigate the role of the protein on metal homeostasis in vivo.

$\mathrm{Ni}$ has previously been suggested to be the key metal ion that binds to EcSlyD and regulates its PPIase activity, ${ }^{[24 a]}$ and its insertion into the apo-enzymes of urease ${ }^{[27]}$ and hydrogenase $^{[28]}$ is the critical process for the maturation of these enzymes. Unexpectedly, we demonstrated herein that little nickel binds HpSlyD in the cell lysates under aerobic 
conditions, even in the presence of excess nickel (10 $\mu \mathrm{M}$ nickel in the culture medium, Figure S6). When the cells expressing $H p S l y D$ were cultured under anaerobic condition, limited amounts of $\mathrm{Ni}$ were found to bind $\mathrm{HpSlyD}$ (ca. $5 \% \mathrm{Ni}$ among total bound metals, Figure S8 in the Supporting Information). It has been shown that the uptake of nickel in cells under aerobic condition is poor, and this may perturb the SlyD function. ${ }^{[29]}$

In summary, the methodology we developed provides a comprehensive and robust approach to readily identify metal-associated proteins as well as to quantify the metals for fast metallome/proteome-wide profiling of metal-binding proteins. By using such a method, the profile of bismuthbinding proteins in $H$. pylori was successfully established, and $H p S l y D$-associated metals in cells were identified. The method can readily be extended to investigate metal (and metallodrug) homeostasis in vivo, considering its high-resolution separation of proteins and sensitive detection of metals. The column-type gel electrophoresis allowed for continuous flow, which is ideal for coupling with ICP-MS for specific metal detection and thus readily extends the application of classical gel electrophoresis to metallomics/metalloproteins. Metallomics and metalloproteomics studies using this approach are under way.

\section{Experimental Section}

H. pylori 26695 (ATCC 700392) $\left(\mathrm{OD}_{600}=0.1-0.2\right)$, in Brucella Broth (Oxoid) with $10 \%$ fetal bovine serum (Gibco), was cultured under microaerobic condition at $37^{\circ} \mathrm{C}$ with constant agitation overnight. Colloidal bismuth subcitrate (Livzon Pharmaceutical Ltd) was added to the medium (at early-log phase) to the final concentration of $20 \mu \mathrm{g} \mathrm{mL}^{-1}$. E. coli strain KMl603 was used for expressing HpSlyD and its variants, and BL21(DE3) and KM1603 were used as controls. Crude cell lysates were directly applied to the demonstrated gel electrophoresis system, which consists of a modified Mini Prep Cell (Bio-Rad) column gel separation system and an ICP-MS detector of 7500a (Agilent Technology) or Elan 6000 (PerkinElmer). The fractions could proceed simultaneously through a T connection splitting the eluted solution before it entered into the detector. The collected fractions were lyophilized and digested with trypsin, followed by a purification step with Ziptip ${ }^{\mathrm{TM}}$ (Millipore), finally characterized with LTQ Orbitrap Velos ${ }^{\mathrm{TM}}$ mass spectrometer (Thermo Scientific). The proteins were identified through the platform of MASCOT Peptide Mass Fingerprinting (www.matrixscience.com). Alternatively, the fractions were further separated with a $1 \mathrm{D}$ slab gel, visualized with silver staining. The protein bands were excised, subjected to trypsin digestion, and identified by peptide mass fingerprinting using the relevant databases. Further details are described in the Supporting Information.

Received: January 29, 2013

Published online: April 2, 2013

Keywords: gel electrophoresis - Helicobacter pylori mass spectrometry $\cdot$ metallomics $\cdot$ metalloproteins

[1] a) A. Changela, K. Chen, Y. Xue, J. Holschen, C. E. Outten, T. V. O'Halloran, A. Mondragon, Science 2003, 301, 1383-1387; b) I. Bertini, H. Gray, E. Stiefel, J. Valentine, Biological Inorganic Chemistry: Structure and Reactivity, University Science Books, 2007.
[2] a) Y. Lu, N. Yeung, N. Sieracki, N. M. Marshall, Nature 2009, 460, $855-862$; b) K. J. Waldron, J. C. Rutherford, D. Ford, N. J. Robinson, Nature 2009, 460, 823-830; c) C. Andreini, I. Bertini, G. Cavallaro, G. L. Holliday, J. M. Thornton, J. Biol. Inorg. Chem. 2008, 13, 1205-1218.

[3] A. Cvetkovic et al., Nature 2010, 466, 779-782; see the Supporting Information.

[4] a) H. de Thé, Z. Chen, Nat. Rev. Cancer 2010, 10, 775-783; b) Z. J. Guo, P. J. Sadler, Angew. Chem. 1999, 111, 1610-1630; Angew. Chem. Int. Ed. 1999, 38, 1512-1531.

[5] a) E. Lengfelder, W. K. Hofmann, D. Nowak, Leukemia 2012 , 26, 433-442; b) Y. W. Jung, S. J. Lippard, Chem. Rev. 2007, 107, 1387-1407; c) S. J. Lippard, Nat. Chem. Biol. 2006, 2, 504-507.

[6] J. Bettmer, Anal. Bioanal. Chem. 2005, 383, 370-371.

[7] a) S. Mounicou, J. Szpunar, R. Lobinski, Chem. Soc. Rev. 2009, 38, 1119-1138; b) S. M. Yannone, S. Hartung, A. L. Menon, M. W. Adams, J. A. Tainer, Curr. Opin. Biotechnol. 2012, 23, $89-$ 95.

[8] H. Sun, Z.-F. Chai, Annu. Rep. Prog. Chem. Sect. A 2010, 106, $20-38$.

[9] C.-N. Tsang, J. Bianga, H. Sun, J. Szpunar, R. Lobinski, Metallomics 2012, 4, 277-283.

[10] R. Lobinski, J. S. Becker, H. Haraguchi, B. Sarkar, Pure Appl. Chem. 2010, 82, $493-504$.

[11] A. M. Sevcenco, M. W. H. Pinkse, H. T. Wolterbeek, P. Verhaert, W. R. Hagen, P. L. Hagedoorn, Metallomics 2011, 3, 1324-1330.

[12] a) R. Lobinski, C. Moulin, R. Ortega, Biochimie 2006, 88, 1591 1604; b) G. Ballihaut, F. Claverie, C. Pecheyran, S. Mounicou, R. Grimaud, R. Lobinski, Anal. Chem. 2007, 79, 6874-6880.

[13] B. J. Marshall, J. R. Warren, Lancet 1984, 323, 1311-1315.

[14] a) S. Suerbaum, P. Michetti, N. Engl. J. Med. 2002, 347, $1175-$ 1186; b) N. Yang, H. Sun, Coord. Chem. Rev. 2007, 251, $2354-$ 2366; c) H. Y. Li, H. Sun, Curr. Opin. Chem. Biol. 2012, 16, $74-$ 83; d) K. H. Thompson, C. Orvig, Science 2003, 300, 936-939.

[15] a) R. G. Ge, H. Sun, Acc. Chem. Res. 2007, 40, 267-274; b) R. G. Ge, X. S. Sun, Q. Gu, R. M. Watt, J. A. Tanner, B. C. Y. Wong, H. H. X. Xia, J. D. Huang, Q. Y. He, H. Sun, J. Biol. Inorg. Chem. 2007, 12, 831-842; c) S. J. Cun, H. Sun, Proc. Natl. Acad. Sci. USA 2010, 107, 4943-4948; d) S. J. Cun, H. Y. Li, R. G. Ge, M. C. M. Lin, H. Sun, J. Biol. Chem. 2008, 283, 15142-15151.

[16] N.-C. Ha, S.-T. Oh, J. Y. Sung, K. A. Cha, M. H. Lee, B.-H. Oh, Nat. Struct. Mol. Biol. 2001, 8, 505-509.

[17] F. J. LaRiviere, A. D. Wolfson, O. C. Uhlenbeck, Science 2001, 294, 165-168.

[18] R. Bryk, P. Griffin, C. Nathan, Nature 2000, 407, 211-215.

[19] N. Handa, T. Terada, Y. Doi-Katayama, H. Hirota, J. R. H. Tame, S. Y. Park, S. Kuramitsu, M. Shirouzu, S. Yokoyama, Protein Sci. 2005, 14, 1004-1010.

[20] D. C. Rees, E. Johnson, O. Lewinson, Nat. Rev. Mol. Cell Biol. 2009, 10, 218-227.

[21] S. K. Pathak, S. Basu, A. Bhattacharyya, S. Pathak, A. Banerjee, J. Basu, M. Kundu, J. Immunol. 2006, 177, 7950-7958.

[22] a) C. Scholz, B. Eckert, F. Hagn, P. Schaarschmidt, J. Balbach, F. X. Schmid, Biochemistry 2006, 45, 20-33; b) T. Cheng, H. Li, W. Xia, H. Sun, J. Biol. Inorg. Chem. 2012, 17, 331-343.

[23] Y. H. Gong, M. Y. Chen, Y. Xu, N. N. Dong, Z. K. Sang, J. Liu, Y. Yuan, FEMS Microbiol. Lett. 2011, 320, 103-109.

[24] a) L. Martino, Y. Z. He, K. L. D. Hands-Taylor, E. R. Valentine, G. Kelly, C. Giancola, M. R. Conte, FEBS J. 2009, 276, 45294544; b) S. Hottenrott, T. Schumann, A. Plückthun, G. Fischer, J. U. Rahfeld, J. Biol. Chem. 1997, 272, 15697-15701; c) C. Wülfing, J. Lombardero, A. Plückthun, J. Biol. Chem. 1994, 269, $2895-2901 ;$ d) K. C. C. Chung, D. B. Zamble, FEBS Lett. 2011, 585, 291 -294; e) H. Kaluarachchi, M. Altenstein, S. R. Sugumar, J. Balbach, D. B. Zamble, C. Haupt, J. Mol. Biol. 2012, 417, $28-35$. 


\section{Angewandte}

Communications

[25] J. J. R. Fraústo da Silva, R. J. P. Williams, The Biological Chemistry of the Elements: The Inorganic Chemistry of Life, Oxford Univeristy Press, Oxford, 2001.

[26] H. Kaluarachchi, D. E. K. Sutherland, A. Young, I. J. Pickering, M. J. Stillman, D. B. Zamble, J. Am. Chem. Soc. 2009, 131, $18489-18500$.
[27] E. L. Benanti, P. T. Chivers, J. Bacteriol. 2009, 191, 2405-2408.

[28] J. W. Zhang, G. Butland, J. F. Greenblatt, A. Emili, D. B. Zamble, J. Biol. Chem. 2005, 280, 4360-4366.

[29] L. F. Wu, M. A. Mandrand-Berthelot, R. Waugh, C. J. Edmonds, S. E. Holt, D. H. Boxer, Mol. Microbiol. 1989, 3, 1709-1718. 